\title{
Conflitos teóricos na pesquisa sobre cinema: em torno de Alphaville, de Godard ${ }^{1}$
}

\section{Renato Luiz Pucci Junior}

\section{Resumo}

0 filme Alphaville (Godard, 1965) é examinado de modo a se mostrar especificidades estilísticas que solicitam um quadro teórico esclarecedor, relacionando pós-modernismo e teoria da narrativa. A análise evidencia a necessidade de um novo programa de pesquisa que oriente formulações teóricas que revisem a historiografia do cinema e TV. Desse modo, tornar-se-ão visíveis os bolsões da produção cinematográfica e televisual ignorados pelo Programa Oposicionista, e distorções de análises poderão ser corrigidas.

\section{Palavras-chave}

Cinema. Pós-modernismo. Godard. Programas de pesquisa.

\section{Introdução}

0 objetivo deste artigo é aprofundar 0 exame de problemas de inadequação teórica para 0 entendimento de parcelas significativas da produção cinematográfica. Pretende-se, com isso, avançar a proposição de um programa de pesquisa que elimine anomalias teóricas enfrentadas pelo Programa 0posicionista, ou seja, que orienta pesquisadores a partir da premissa de oposição ao cinema narrativo clássico (BORDWELL, 1997, p. 83-115). ${ }^{2}$

Há continuidade em relação ao artigo (PUCCI JR., 2007) em que foi examinada a anomalia constituída pelo terceiro longa-metragem de Godard, Uma Mulher é uma Mulher, lançado em 1961. Naquele texto, apresentavam-se consequências da desatenção da crítica orientada pelo Programa Oposicionista, com reflexos na falta de visibilidade de vínculos entre Uma Mulher é uma Mulher e a produção televisual de Guel Arraes.

Já então era apontada a necessidade de reexaminar Alphaville (Godard, 1965), pois
Doutor em Ciências da Comunicação pela Escola de Comunicação e Artes da Universidade de São Paulo - ECA-USP. Professor da Universidade Tuiuti do Paraná - UTP. 
havia sinais de que é parcialmente questionável sua caracterização pela crítica. Não se trata de repetição de análise, pois a necessidade de voltar o foco para Alphaville decorre do tratamento diferenciado que tem recebido. 0 indício central de que Uma Mulher é uma Mulher constitui um problema para adeptos do Programa Oposicionista consiste em ter sido relegado a um plano irrelevante em comparação com os demais títulos da filmografia de Godard. Conclui-se que aqueles críticos não dispunham de um aparato teórico capaz de dar conta do pós-modernismo do filme, por isso ignoraram a anomalia (no sentido de evidência empírica contrária) em benefício dos resultados positivos obtidos pelo programa de pesquisa. Em contraposição, Alphaville é um título lembrado pela crítica oposicionista, ainda que jamais tenha tido o prestígio de Pierrot le fou (1965) ou Passion (1982). ${ }^{3}$ Espero mostrar que esse interesse oculta problemas semelhantes aos causados pelo outro filme, ou seja, que Alphaville também constitui uma anomalia, o que resulta em tergiversações a fim de enquadrá-lo no quadro teórico e historiográfico disponível, novamente com resultados prejudiciais ao entendimento não só da primeira fase de Godard como também da produção audiovisual de décadas posteriores.

A proposta articula-se à necessidade de maior reflexão teórica com fins heurísticos. Não se trata da aplicação de procedimentos hermenêuticos sobre Alphaville, mesmo porque é irretocável muito da interpretação que dele já se realizou, e muito menos de propor uma nova apreciação estética, uma vez que possivelmente Alphaville possua os méritos que a crítica tem apontado. Trata-se de indicar problemas e possíveis soluções, no sentido da revisão teórica e historiográfica que já vem ocorrendo há décadas na pesquisa internacional (BORDWELL, 1997, p. 120-127) e há alguns anos no âmbito nacional (PUCCI JR., 2007).

Portanto, a análise não será exaustiva, mas se fará apenas na medida em que revelar aspectos que estejam obscurecidos em função de problemas teóricos. ${ }^{4}$

Uma versão deste artigo foi apresentada no GT Fotografia, Cinema e Vídeo, do XVII Encontro da Compós, realizado na UNIP, em São Paulo (SP), em junho de 2008.

Bordwell (1997, p. 9) se fundamenta no filósofo Larry Laudan (1977), cuja teoria sobre a Ciência faz uso da expressão research tradition, com implicações relativas à noção de anomalia e à comparação entre diferentes programas/tradições. Permaneço com a concepção de Lakatos, que me parece mais sustentável: programas de pesquisa ("research programs") são tradições de pesquisa com regras metodológicas definidas por heurísticas negativa e positiva, de modo que os programas são comparáveis entre si pela avaliação da transferência de problemas, numa operação capaz de detectar se essa transferência é teoricamente progressiva ou regressiva (LAKATOS, 1979, p. 144).

Haja vista a mínima atenção de Deleuze a Alphaville: duas linhas em A Imagem-Tempo (1990, p. 314), em contraste com a enorme atenção dedicada a outros filmes de Godard. Como bem assinalou Andréa França no debate do GT Fotografia, Cinema e Vídeo, na Compós de 2008, Deleuze dedica parte de A Imagem-Movimento ao cinema hollywoodiano, sem o teor agressivo dos críticos que a ele se opõem. Essa cinematografia constitui o que denominou a imagem-ação. No entanto, como expliquei no debate, a abordagem deleuziana da produção hollywoodiana não ultrapassa meados dos anos sessenta: "por aí não passa mais a alma do cinema" (DELEUZE, 1985, p. 253). A produção posterior não merece a mais insignificante atenção, o que, a meu ver, caracteriza Deleuze como oposicionista em relação ao cinema mainstream da época em que escreveu os seus livros sobre cinema. 


\section{Alphaville, a última incursão amistosa de Godard no cinema de gênero}

Alphaville foi o décimo longa-metragem dirigido

por Godard, que à altura de seu lançamento, em 1965, consolidava a imagem de cineasta transgressivo e provocador que se perpetuaria nas décadas seguintes. Após o sucesso de público com Acossado (1959), Godard oscilou entre a linha modernista, portanto de difícil acesso ao espectador comum, com, por exemplo, O Pequeno Soldado (1960), Viver a Vida (1962), Tempo de Guerra (1963) e O Desprezo (1963), e ao menos um filme mais acessível, Uma Mulher é uma Mulher. Oscilava entre a oposição à narrativa clássica do cinema hollywoodiano e um filme com estrutura paradoxal tipicamente pós-modernista, a combinar a composição dirigida para a alta comunicação com 0 grande público e distanciamento modernista. ${ }^{5}$

Houve ainda Band à part (1964), com seu espalhafatoso happy end, verdadeira paródia lúdica do cinema hollywoodiano, traço pós-modernista que não se confirma no restante do filme.
É nessa trajetória que surge Alphaville. Ainda que parte da crítica não hesite em concluir pelo seu caráter modernista, ${ }^{6}$ é possível questionar essa proposição.

Bastará um breve resumo da trama para que seja possível introduzir os pontos que serão desenvolvidos no presente artigo. 0 agente secreto Lemmy Caution (interpretado pelo americano Eddie Constantine, que já fizera o mesmo papel várias vezes desde os anos cinquenta, em filmes franceses de outros diretores) chega a Alphaville, cidade de um futuro indefinido, porém não muito distante, que é controlada pelo computador Alpha 60. A missão de Caution é trazer o Dr. von Braun, criador de Alpha 60, de volta aos Espaços Exteriores, a fim de evitar uma guerra intergaláctica. Alphaville é uma sociedade planejada, em que até as palavras em circulação são controladas pelo computador, de modo que 0 horizonte existencial de cada habitante se encontra artificialmente limitado. ${ }^{7}$ Caution

No GT Fotografia, Cinema e Vídeo, na Compós de 2008, Mariarosaria Fabris alegou que as teorias operam com a estatística, isto é, que estudos teóricos são feitos por amostragem e, portanto, exceções são deixadas de lado, mas não porque tenham sido ignoradas. Meu argumento, na verdade, segue a mesma premissa, embora com outra conclusão: na fase de estabelecimento de uma teoria (ou programa de pesquisa), as anomalias precisam ser deixadas de lado para que resultados promissores não sejam prejudicados. É como se preserva o núcleo do programa (LAKATOS, 1979, p. 163-165). Ocorre que, a partir de algum momento, o número de anomalias pode crescer a um ponto preocupante, quando então o programa de pesquisa vigente deve explicá-las, incorporando-as como exemplo corroborador de si próprio, ou submeter-se ao ataque de programas rivais, que pretendem dar conta das anomalias indicadas (ibidem, p. 195-196).

Em Pucci Jr. (2007), foi indicado que o caráter pós-modernista de Uma Mulher é uma Mulher antecede em cerca de vinte anos a disseminação do pós-modernismo no cinema.

Caso de Parente (1998, p. 77-89).

0 que retoma a novilíngua descrita em 1984, distopia modelar de George Orwell. MacLean (1977/1978) associa Alphaville à concepção do filósofo Ludwig Wittgenstein, exposta no Tractatus Logico-Philosophicus, quanto à importância das palavras para a definição do mundo de cada pessoa. 
conhece Natasha (Anna Karina), filha de von Braun, e se apaixona por ela. Caution mata von Braun, inicia o processo de destruição de Alphaville e salva Natasha quando fogem para 0 exterior.

Tornou-se um lugar-comum da crítica apontar que a produção foi realizada com imagens contemporâneas de Paris, sem cenários futurísticos e sem 0 aparato de produção e de efeitos especiais que se tornaram comuns no gênero, em especial desde 0 final da década de sessenta. Alpha 60, o computador que controla Alphaville, não passa de um ventilador pequeno, iluminado por baixo (GODARD, 1989, p. 98), bem distante da imensa máquina de 2001 - Uma Odisséia no Espaço (Kubrick, 1968). Todos os efeitos futuristas são obtidos com o cenário urbano de Paris e objetos triviais, a partir de ângulos e iluminação inusitados. ${ }^{8}$

Alphaville constitui um exemplo de distopia da ficção científica e, obviamente, não passou despercebido à crítica que a contemporaneidade das imagens remetia à própria época em que foi realizado. Nessa perspectiva, a Paris moderna de meados dos anos sessenta, com seus arranhacéus envidraçados, já seria a encarnação de um apocalipse tecnicista. ${ }^{9}$

Alphaville é um filme complexo, com uma estrutura multifacetada e composição rica em termos narrativos, iconográficos e intertextuais. ${ }^{10}$ Com mais de quarenta anos de recuo histórico, ainda pode causar perplexidade a estranha combinação de elementos da cultura midiática e recursos de extração modernista. A lista do primeiro desses grupos é longa, mas merece ser enumerada:

a) Composição audiovisual de filme noir: aspecto visual predominantemente noturno ou sombrio; voz over do personagem principal, que narra a história, como acontecia em Pacto de Sangue (Billy Wilder, 1944), entre outros noir;

b) Protagonista caracterizado à maneira do detetive hard-boiled, como Philip Marlowe, de À Beira do Abismo (Howard Hawks, 1946): impermeável, chapéu característico, falas rudes ("Sou velho demais para discutir horas a fio. Por isso atiro"), durão com as mulheres (diz

Bergala (2006, p. 226-251) descreve o difícil processo de produção de Alphaville, que exigiu um plano de trabalho minucioso, trabalho lento em boa parte das filmagens e a ultrapassagem dos prazos do cronograma, elementos inexistentes na realização dos demais filmes de Godard nos anos sessenta. Pode-se pensar que a diferença decorre do projeto, que criou problemas para um cineasta que não dispunha dos recursos de um sistema industrial, onde normalmente se fizeram os filmes de ficção científica, mesmo de baixo orçamento.

Sobre a relação contextual do mundo diegético de Alphaville e a Paris dos anos sessenta, ver Darke (1994). Curiosamente, modernos edifícios não são tão numerosos assim nem hoje em dia, quase que inteiramente restritos ao Quartier de La Défense, onde Alphaville foi em parte filmado.

0 mérito de Parente (1998) é apontar essa estrutura complexa. Alphaville não é um filme modernista tout court, isto é, pautado exclusivamente pelo princípio da originalidade e com estruturas de agressão, mas conta também com elementos clássicos e poéticos. Como será visto adiante, o que é problematizável é a conclusão que Parente retira dessa estrutura. 
"Cai fora!" às lindas sedutoras do hotel e, sem motivo plausível, esbofeteia uma delas), sempre em risco de morrer ("Para um simples agente secreto, [a morte] é normal como o whisky. E bebi a vida toda");11

c) 0 protagonista diz que 0 sorriso e os dentinhos pontudos de Natasha lembram os velhos filmes de vampiros projetados nos museus (alusão a produções da Universal ou da Hammer, estúdios populares nos anos trinta e sessenta, respectivamente);

d) Um personagem desaparecido é chamado de Dick Tracy, nome do memorável detetive dos quadrinhos;

e) Durante a cena de fuzilamento na piscina, os saltos em sucessão das nadadoras e alguns de seus movimentos na água lembram coreografias de Busby Berkeley, como em O Meu Boi Morreu (The Kidfrom Spain, Leo McCarey, 1932);

f) Agente 003, codinome atribuído a Caution, é óbvia referência a James Bond, 0 agente 007, então no auge da popularidade, em títulos como 007 Contra Goldfinger (Guy Hamilton, 1964); o trecho em que Caution é atacado numa cabine telefônica é similar a cenas desses filmes;

g) A trilha de suspense, por vezes exagerada, pontua as cenas quase sempre à maneira do cinema clássico; h) Leitmotiv romântico a cada vez que Natasha está presente (quando se escuta essa música na escuridão da sala do Institute de Sémantique Generale, já se adivinha que Natasha está ali). 0 mesmo recurso é utilizado com as sedutoras dos hotéis;

i) Caution passa o dedo nos lábios, célebre gesto de personagens de Humphrey Bogart;

j) Gags, como a da máquina em que Caution põe a moeda e que lhe devolve um cartão com a palavra "Merci", ou a da subida de Caution pela escadaria do hotel, quando aproveita para lustrar os sapatos no tapete;

k) Romantismo exacerbado no espírito de filmes hollywoodianos: Natasha, que sequer conhecia o significado de estar apaixonada, ao ouvir a palavra "amor" acorda do transe hipnótico a que fora submetida no interrogatório; e quando, no desfecho, aprende a falar "Eu te amo", escuta-se uma trilha de épico romântico, à maneira por exemplo de Dr. Jivago (David Lean, 1965);

l) Happy end: o casal amoroso foge de carro para os países exteriores e se salva da destruição de Alphaville.

Ressalte-se que 0 tom das referências à cultura midiática nunca é agressivo, ao contrário do que já fizera o próprio Godard em outros filmes e faria inesgotavelmente nos posteriores, como Pierrot le fou e Made in USA (1967). No conjunto, as 
relações apontadas fazem de Alphaville um aglomerado intertextual com pouco ou nenhum teor crítico em relação aos seus objetos, no que se alinha a tantos filmes lançados a partir dos anos oitenta, como Blade Runner, o Caçador de Andróides (Ridley Scott, 1982), Hammett, o Falcão Maltês (Wim Wenders, 1982), Brazil, o Filme (Terry Gilliam, 1985) e, no cinema nacional, A Dama do Cine Shangai (Guilherme de Almeida Prado, 1988). Note-se que, desde os anos oitenta, diversos críticos apontaram que então o cinema havia renunciado aos ideais modernistas de originalidade e autenticidade. ${ }^{12}$

Em relação aos filmes de detetives e de espionagem, Alphaville é uma paródia lúdica, forma intertextual típica do pós-modernismo: diferença irônica na semelhança e transgressão sancionada da convenção (HUTCHEON, 1991, p. 12). As marcas de ironia intertextual são claras, por exemplo, no tom acima da naturalidade em cenas como a do brado romântico de Caution para os inimigos, ao retirar Natasha da sala de interrogatórios: "Somos a felicidade e vamos ao seu encontro!". Entenda-se bem esse ponto. Godard sempre trabalhou com a intertextualidade, fez inúmeras paródias, como em Tempo de Guerra (1963) e Detetive (1985); entretanto, quase sempre operou com a paródia modernista, cujo sentido é corrosivo em relação ao objeto parodiado e que, em razão do ideal de originalidade, produz a "grande divisão" entre alta cultura e cultura de massa (HUYSSEN, 1986). A paródia lúdica pós-modernista trabalha com o familiar ao grande público e, mesmo que sempre exista uma aresta crítica, não rompe necessariamente a comunicação. ${ }^{13}$

Filmes pós-modernos levam em conta o prazer do grande público, propondo-lhe um jogo mnemônico com o repertório da cultura midiática, ao mesmo tempo em que não renunciam a uma seriedade básica (HUTCHEON, 1991, p. 175). Em outras palavras, a intenção crítica não destrói obrigatoriamente o prazer do público. Veja-se, como exemplo, a cena em que Natasha declama versos de Paul Éluard, em enquadramentos que ressaltam a beleza da atriz Anna Karina, ou a mulher totalmente nua, de joelhos e de costas, num engradado de vidro, como uma estátua viva — em ambos os casos, critica-se a sociedade totalitária de Alphaville, que aboliu a palavra "amor" e programou a sexualidade, mas também se contrariam princípios modernistas de ascetismo que renegam o tipo de prazer espectatorial que aquelas cenas poderiam provocar.

Como se depreende da "análise comparativa" feita por Parente (1998, p. 85-86, 134) entre Alphaville e Blade Runner, totalmente desfavorável ao segundo filme.

Nem sempre a bilheteria é um indicador seguro da comunicação com o público; contudo, registre-se que Alphaville teve 112.626 espectadores em sete semanas de exibição em Paris, enquanto Tempo de Guerra, com suas desconcertantes rupturas de linguagem, não passou de 20.923 (BERGALA, 2006, p. 140 e 249). Michel Marie registra quanto a Tempo de Guerra "menos de 3.000 espectadores em duas semanas de exibição em Paris em junho de 1963” (2006, p. 11). De qualquer maneira, um desastre de bilheteria, que indica a mudança de rumo na filmografia de Godard. 
Não podem ser desconsiderados os letreiros em neon e outros tipos de luminosos, que cerca de quinze anos depois se tornariam comum em filmes pós-modernos, como O Fundo do Coração (Coppola, 1982) e Subway (Luc Besson, 1985) e, no Brasil, em Cidade Oculta (Francisco Botelho, 1986) e Anjos da Noite (Wilson Barros, 1987).

Em Alphaville, ao menos sete vezes piscam letreiros de neon a ocupar toda a tela (três vezes com $\mathrm{E}=\mathrm{mc}^{2}$ ), além de outras fontes luminosas, como uma seta apontando para o lado (mero led de painel, mas que, fora de contexto e em enquadramento fechado, ou seja, enorme na tela, potencializa-se visualmente e pode provocar estranhamento). ${ }^{14}$

0 traço mais familiar aos espectadores comuns está na montagem, que deixa de ser clássica apenas em momentos precisos, como será visto adiante. Em geral, subsiste a narrativa clássica, em coexistência com descontinuidades e intrusões da narração, resultando na alternância em alta frequência entre naturalismo e antinaturalismo, ${ }^{15}$ traço do pós-modernismo cinematográfico (PUCCI JR., 2003, p. 36-41; p. 175-179).

Entretanto, o pós-modernismo não se limita, a não ser em caracterizações simplórias, à intertextualidade com a cultura midiática. $\mathrm{Na}$ acepção aqui adotada, o pós-modernismo se define pelo caráter paradoxal, que, por exemplo, associa referentes familiares ao grande público a uma sofisticação que lhe é estranha. Em Alphaville, esse encontro paradoxal ocorre entre os elementos clássicos, principalmente de gênero, e outros dois campos: o poético e o modernista. ${ }^{16}$

A princípio, a presença de características poéticas em Alphaville é intermitente, até culminar na esplêndida cena em que Natasha declama fragmentos de poemas de Capitale de la douleur, livro de Paul Éluard. A combinação audiovisual chega a um nível que se poderia chamar de sublime, com primeiros planos de Natasha, fades, contraluz, plano de detalhe de seu olho, superexposição, um balé de primeiros planos dela e de Lemmy Caution, tudo em conjunção harmoniosa com a melodia ou o silêncio. Em termos de acessibilidade do grande público, observe-se a distância entre esse trecho e cenas como a da gag da máquina que "engole" a moeda de Caution e a dos sapatos na escadaria do hotel, potencialmente compreensíveis por um público muito amplo. Eis como coexistem, no mesmo filme, componentes heterogêneos.

0 segundo nível de sofisticação se constitui no âmbito da linguagem cinematográfica,

Esse traço de filmes dos anos oitenta foi tão marcante que originou a expressão "neon-realismo" para designá-los. Nos anos noventa e seguintes, o neon perdeu sua onipresença, mas filmes pós-modernos continuaram a existir (PUCCI JR., 2003, p. 227-268). 
em especial no que diz respeito à montagem.

Ainda que existam cenas em que predomine a montagem clássica, há frequentes e ostensivas descontinuidades e intrusões da narração:

a) Quando retorna ao hotel, Caution abre sucessivas portas do quarto, atrás das quais Natasha está sempre escondida, o que seria inadequado numa montagem clássica, isto é, que respeitasse a continuidade de espaço e tempo;

b) Imagens em negativo: na fuga de Caution do segundo interrogatório feito pelo computador, na luta contra o segurança na garagem, nos corredores do prédio em que Natasha está aprisionada e na perseguição com automóveis. Recurso utilizado em Nosferatu (Murnau, 1922) com a função de acentuar 0 aspecto sobrenatural da trama, em Alphaville constitui intrusões da narração, que seriam despropositadas em relação à verossimilhança de uma narração exclusivamente clássica;

c) Trilha sonora de suspense algumas vezes em desacordo com a cena, por exemplo, durante a gag dos sapatos na escadaria do hotel; d) Olhares para a câmera, de Natasha e Caution, quando ela põe a mão na frente do rosto dele, na cena do poema;

e) Quebras de eixo, como no quarto de Henry Dickson, o espião decadente interpretado por Akim Tamiroff, quando Caution abre a porta do guarda-roupa. ${ }^{17}$

Esses elementos constituem rupturas em relação ao estilo clássico que, como visto, orienta partes consideráveis da narração. Já é possível, portanto, sustentar a caracterização de Alphaville como um filme pós-modernista, em vista de seu caráter paradoxal, que combina aspectos familiares ao grande público com sofisticação poética e modernista. ${ }^{18}$ Não se trata em absoluto de definir Godard como um cineasta pós-modernista, mesmo porque até mesmo nessa fase predominaram filmes modernistas, enquanto nas seguintes estes prevaleceram sem exceção (PUCCI JR., 2007). Trata-se de confirmar a impressionante precocidade do cineasta em relação ao pós-modernismo, que já se consolidava na arquitetura, literatura e artes plásticas, mas

Parente (1998, p. 82) acrescenta o movimento "browniano" de câmera e dá como exemplo a cena em que Caution vai à casa de máquinas, o centro nervoso de Alphaville. Não é possível concordar com a qualificação de "browniano" (que alude ao movimento aleatório de partículas em suspensão), pois aquele movimento de câmera é aleatório apenas em relação à padronização clássica, mas possui sentido numa narração modernista, podendo inclusive se tornar previsível: a câmera deixa Caution, gira pelo cenário e, claro, o reencontra adiante. Rompe-se por instantes a norma clássica de direcionamento narrativo para o personagem, mas em vista de outras funções.

Não é essa a conclusão a que chega Parente. Após indicar a tríplice estrutura de Alphaville (1998, p. 77-84), o autor conclui enfatizando apenas os "movimentos espirituais aberrantes" que fazem do filme um representante do "automatismo cinematográfico moderno", minimizando a relevância dos elementos clássicos e de fácil assimilação pelo grande público (p. 86). É pertinente indagar o que seria um filme com aquela tríplice estrutura dentro de seu quadro teórico, a teoria deleuziana, que não apresenta menção direta ao pós-modernismo. Quando Parente propõe que se faça uma análise comparativa entre 0 Bandido da Luz Vermelha e Anjos da Noite nos moldes da que diz ter realizado entre Alphaville e Blade Runner (1998, p. 134), pressente-se que características pós-modernas do filme de Wilson Barros serão indevidamente menosprezadas. 
demoraria ainda década e meia para se implantar no campo cinematográfico.

\section{Um contexto de guerra cultural}

Foi dito no início que Godard oscilava entre a realização de filmes modernistas e pósmodernistas (incluindo Alphaville, como se viu acima). Os motivos para essa oscilação foram levantados por Esquenazi (2004). 0 fim dos anos cinquenta, na França, parecia trazer o fim da fronteira entre cultura clássica e industrial (ibidem, p. 17-64) quando as trocas seriam possíveis (ibidem, p. 268). Os jovens cineastas da Nouvelle Vague, todos amantes do cinema americano, inclusive Godard, realizavam filmes que operavam com os dois registros, 0 que possibilitou sucessos de bilheteria: Nas Garras do Vício (Claude Chabrol, 1958), Os Incompreendidos (Truffaut, 1959) e Acossado. Evidentemente, não basta uma boa bilheteria para que se caracterizem filmes como pósmodernistas (o que sem dúvida não eram os dois primeiros títulos), todavia o início da Nouvelle Vague fazia ouvir a voz dos amantes do cinema comum (ibidem, p. 43), o que não poderia agradar à elite letrada francesa.

A reação da crítica foi fulgurante (ibidem, $p$. 93-107, 268). A partir do primeiro fracasso de bilheteria, Uma Mulher é uma Mulher, a rejeição da intelectualidade francesa se fez evidente. O Pequeno Soldado, produzido em 1960, imediatamente censurado pelo governo gaullista e lançado comercialmente apenas em 1963, provocou reações ainda mais drásticas. Hoje pouco se recorda que, enquanto Acossado deixou perplexa a crítica francesa (calada pela surpresa e pela aceitação do grande público), filmes posteriores foram alvo de ataques sistemáticos e impiedosos, tanto por parte da crítica de direita como de esquerda, sempre na chave da cultura erudita. O Pequeno Soldado, que ousava tratar 0 problema da Guerra da Argélia com um mínimo de leveza (pois seu protagonista se define pela cultura industrial), recebeu qualificações tão inequívocas quanto as de "vagabundagem intelectual" e "fascismo nostálgico" (ESQUENAZI, 2004, p. 99).

A lógica cultural francesa iria enquadrar os rebeldes (ibidem, p. 125): Truffaut deriva para o filme com fundo literário (Jules et Jim, 1961) e Godard resiste 0 quanto pode, oscila da forma acima indicada, cede gradativamente terreno às exigências de sofisticação erudita, até que, a partir de Pierrot le fou (1965), assume em definitivo a linha modernista, que, na terminologia de Esquenazi, é uma das variações do que chamou de "cultura clássica", que obedece à lógica da raridade das obras a serem valorizadas (ibidem, p. 20-22). ${ }^{19}$

Alphaville se inscreve nos embates culturais desse contexto. Foi a derradeira tentativa de 
Godard em vista do sucesso de crítica com uma poética não-clássica. Diga-se de passagem que não é cabível recriminar 0 cineasta por abandonar 0 terreno que parecia tão promissor para 0 cinema: se no Brasil, cuja tradição erudita é precária, aconteceram ataques furiosos aos cineastas que enveredaram pelo cinema pósmoderno (ou, talvez pior, concederam-lhes 0 silêncio absoluto), como menosprezar a pressão arrasadora da intelectualidade francesa, com séculos de tradição letrada?

\section{Conclusão}

A comparação entre diferentes programas de pesquisa ou teorias é um dos problemas vitais da Filosofia da Ciência, variando as respostas desde a que supõe a absoluta impossibilidade de comparação devido à incomensurabilidade (Thomas Kuhn) até o popperianismo sofisticado de Lakatos, que considerava como fator decisivo o ganho empírico dos programas na resolução de anomalias. ${ }^{20}$

Distante de qualquer viés relativista, propõe-se aqui que o Programa 0posicionista, por recusar atenção a aspectos do cinema clássico e suas apropriações não-modernistas, esbarra em anomalias de difícil solução. Com o programa revisionista, que Bordwell (1997, p. 120-127) chamou de piecemeal history, cujo princípio heurístico rejeita a adoção de uma forma específica de cinema como modelo exclusivo de realização, é possível que largas extensões da produção cinematográfica e televisual passem a fazer parte do mundo construído pela pesquisa científica, ou, no caso de já a ele pertencerem, que surjam com novos aspectos antes ignorados ou minimizados.

Em combinação com o artigo sobre Uma Mulher é uma Mulher, o exame de Alphaville mostra um dos papéis de uma revisão historiográfica. Na verdade, é possível que em relação ao audiovisual brasileiro os resultados sejam ainda mais surpreendentes, em razão dos vastos bolsões de filmes e programas de TV nacionais que até há poucos anos jamais tinham sido devidamente pesquisados, a não ser esporadicamente ou de forma negativa (pelo prisma do Programa 0posicionista): cinema mudo, comédias musicais, chanchadas, filmes policiais, pornochanchada, ficção televisual etc.

20 No referido debate do GT Fotografia, Cinema e Vídeo, Maurício Lissovsky objetou contra o tratamento dos estudos de cinema segundo parâmetros das Ciências Exatas. Argumentou que nestas uma teoria tem que estar errada quando confrontada com outra, 0 que levaria necessariamente à sua indiscutível refutação, 0 que nunca ocorreria na área de Humanas. Há nessa réplica uma idealização do processo do conhecimento científico na área de Exatas, como se nesta não houvesse polêmicas aguerridas e duradouras. Disse Lakatos, porém, que as experiências cruciais, supostamente decisivas em qualquer questão teórica, são batalhas que não determinam necessariamente o fim da guerra (1979, p. 194-195). À parte inegáveis diferenças entre as Ciências Exatas e pesquisas em campos como 0 do cinema, pode-se dizer que têm em comum o intenso confronto teórico, com muita relutância de adeptos de teorias em crise em abandoná-las. 0 texto em que me baseio (LAKATOS, 1979), que aborda a chamada hard science, é repleto de exemplos de conflitos de difícil solução. Não é menosprezável que Thomas Kuhn (1978, p. 192) tenha assinalado que a resistência dos adeptos de uma teoria em crise somente termina quando eles envelhecem e morrem. Edgar Morin, por exemplo em Ciência com consciência (2003, passim), cujo escopo inclui as Ciências Exatas, não dá mostras de acatar a ideia de conflitos pontuais, facilmente solucionáveis, mesmo porque então a ciência não seria complexa. 
Daí a relevância de formulações teóricas, como a do Cinema de Bordas (LYRA; SANTANA, 2006) ou do pós-modernismo, que deem conta desse passado cinematográfico e, quem sabe, iluminem 0 presente.

\section{Referências bibliográficas}

BERGALA, Alain. Godard au travail: les années 60 .

Paris: Cahiers du Cinéma, 2006.

BORDWELL, David. On the history of film style.

Cambridge: Harvard University Press, 1997.

DARKE, Christian. It all happened in Paris. Sight and Sound, Londres, vol. 4, n. 7, p. 10-12, jul. 1994.

DELEUZE, Gilles. A imagem-movimento. São Paulo: Brasiliense, 1985.

A imagem-tempo. São Paulo: Brasiliense, 1990.

ESQUENAZI, Jean-Pierre. Godard et la société

française des années 1960. Paris: Armand Colin, 2004.

GODARD, Jean-Luc. Introdução a uma verdadeira

história do cinema. São Paulo: Martins Fontes, 1989.

HUTCHEON, Linda. Poética do pós-modernismo. Rio de Janeiro: Imago, 1991.

HUYSSEN, Andreas. After the great divide: modernism, mass culture and postmodernism. Londres: Macmillan Press, 1986.

KUHN, Thomas. A estrutura das revoluções científicas. 2. ed. São Paulo: Perspectiva, 1978.

LAKATOS, Imre. 0 falseamento e a metodologia dos programas de pesquisa científica. In: LAKATOS, Imre.; MUSGRAVE, Alan. (orgs.). A crítica e o desenvolvimento do conhecimento. São Paulo: Cultrix, 1979. p. 109-243.

LAUDAN, Larry. Progress and its problems: towards a theory of scientific growth. Berkeley: University of California Press, 1977.
LYRA, Bernadette; SANTANA, Gelson (orgs.). Cinema de bordas. São Paulo: Ed. do Autor, 2006.

MACLEAN, Robert. Opening the private eye: Wittgenstein and Godard's Alphaville. Sight and Sound, Londres, v. 47, n. 1, p. 46-49, winter 1977-1978. MARIE, Michel. Comprendre Godard: travelling avant sur À bout de souffle et Le mépris. Paris: Armand Colin, 2006.

MORIN, Edgar. Ciência com consciência. 7. ed. Rio de Janeiro: Bertrand Brasil, 2003.

PARENTE, André. Ensaios sobre o cinema do simulacro. Rio de Janeiro: Pazulin, 1998.

PUCCI JR., Renato Luiz. Cinema brasileiro pósmoderno: estilo paradoxal, em direção a uma poética. 2003. Tese (doutorado em Ciências da Comunicação)Escola de Comunicações e Artes, Universidade de São Paulo, São Paulo, 2003.

Programas de pesquisa sobre 0 audiovisual: anomalias em Godard e Guel Arraes. E-Compós, Brasília, n. 9, ago. 2007. Disponível em: <http://www. compos.org.br/seer/index.php/e-compos/article/ view/184/185>. Acesso em: 30 set. 2008. 
Theoretical conflicts in the research on cinema: about Godard's Alphaville

\section{Abstract}

The film Alphaville (Godard, 1965) is analyzed here in order to expose stylistic details which ask for a clarifying theoretical framework, connecting postmodernism and narrative theory. The analisys states the need of a research program that offers theoretical formulations which will revise cinema and television's historiography, and points out the large extension of cinematographic and televisive production ignored by the oppositional program, or to correct analytical distortions.

\section{Keywords}

Cinema. Postmodernism. Godard. Research programs.

\section{Conflictos teóricos en la investigación sobre cine: acerca de Alphaville, de Godard}

\section{Resumen}

La película Alphaville (Godard, 1965) es examinada con el propósito de enseñar las peculiaridades estilísticas que buscan aclarar un marco teórico, relacionando el posmodernismo y la teoría de la narrativa. El objetivo es destacar la necesidad de un programa de investigación para orientar las formulaciones teóricas que revisen la historiografía del cine y de la televisión, además de poner en relieve las producciones del cine y de la televisión que son ignoradas por el Programa de Oposición o para que sean analizadas de forma más adecuadas.

\section{Palabras clave}

Cine. Posmodernismo. Godard.

Programas de investigación. 


\section{Expediente}

A revista E-Compós é a publicação científica em formato eletrônico da Associação Nacional dos Programas de Pós-Graduação em Comunicação (Compós). Lançada em 2004, tem como principal finalidade difundir a produção acadêmica de pesquisadores da área de Comunicação, inseridos em instituições do Brasil e do exterior.
E-COMPÓS I www.e-compos.org.br I E-ISSN 1808-2599

Revista da Associação Nacional dos Programas de Pós-Graduação em Comunicação. Brasília, v.12, n.1, jan./abr. 2009.

A identificação das edições, a partir de 2008 passa a ser volume anual com três números.

\section{CONSELHO EDITORIAL}

\section{Afonso Albuquerque}

Universidade Federal Fluminense, Brasil

Alberto Carlos Augusto Klein

Universidade Estadual de Londrina, Brasi

Alex Fernando Teixeira Primo

Universidade Federal do Rio Grande do Sul, Brasil

\section{Alfredo Vizeu}

Universidade Federal de Pernambuco, Brasil

Ana Carolina Damboriarena Escosteguy

Pontifícia Universidade Católica do Rio Grande do Sul, Bras

Ana Silvia Lopes Davi Médola

Universidade Estadual Paulista, Brasil

André Luiz Martins Lemos

Universidade Federal da Bahia, Brasil

Ângela Freire Prysthon

Universidade Federal de Pernambuco, Brasil

Antônio Fausto Neto

Universidade do Vale do Rio dos Sinos, Brasil

Antonio Carlos Hohlfeldt

Pontifícia Universidade Católica do Rio Grande do Sul, Brasil

Arlindo Ribeiro Machado

Universidade de São Paulo, Brasil

César Geraldo Guimarães

Universidade Federal de Minas Gerais, Brasil

Cristiane Freitas Gutfreind

Pontifícia Universidade Católica do Rio Grande do Sul, Brasil

Denilson Lopes

Universidade Federal do Rio de Janeiro, Brasil

Eduardo Peñuela Cañizal

Universidade Paulista, Brasi

Erick Felinto de Oliveira

Universidade do Estado do Rio de Janeiro, Brasil

Francisco Menezes Martins

Universidade Tuiuti do Paraná, Brasil

Gelson Santana

Universidade Anhembi/Morumbi, Brasi

Hector Ospina

Universidad de Manizales, Colômbia

leda Tucherman

Universidade Federal do Rio de Janeiro, Brasil

Itania Maria Mota Gomes

Universidade Federal da Bahia, Brasil

Janice Caiafa

Universidade Federal do Rio de Janeiro, Brasil

Jeder Silveira Janotti Junior

Universidade Federal da Bahia, Brasil
João Freire Filho

Universidade Federal do Rio de Janeiro, Brasil

John DH Downing

University of Texas at Austin, Estados Unidos

José Luiz Aidar Prado

Pontifícia Universidade Católica de São Paulo, Brasil

José Luiz Warren Jardim Gomes Braga

Universidade do Vale do Rio dos Sinos, Brasil

Juremir Machado da Silva

Pontifícia Universidade Católica do Rio Grande do Sul, Brasil

Lorraine Leu

University of Bristol, Grã-Bretanha

Luiz Claudio Martino

Universidade de Brasília, Brasil

Maria Immacolata Vassallo de Lopes

Universidade de São Paulo, Brasil

Maria Lucia Santaella

Pontifícia Universidade Católica de São Paulo, Brasil

Mauro Pereira Porto

Tulane University, Estados Unidos

Muniz Sodre de Araujo Cabral

Universidade Federal do Rio de Janeiro, Brasil

Nilda Aparecida Jacks

Universidade Federal do Rio Grande do Sul, Brasil

Paulo Roberto Gibaldi Vaz

Universidade Federal do Rio de Janeiro, Brasil

Renato Cordeiro Gomes

Pontifícia Universidade Católica do Rio de Janeiro, Brasil

Ronaldo George Hela

Universidade do Estado do Rio de Janeiro, Brasil

Rosana de Lima Soares

Universidade de São Paulo, Brasil

Rossana Reguillo

Instituto Tecnológico y de Estudios Superiores do Occidente, México

Rousiley Celi Moreira Maia

Universidade Federal de Minas Gerais, Brasil

Sebastião Carlos de Morais Squirra

Universidade Metodista de São Paulo, Brasi

Simone Maria Andrade Pereira de Sá

Universidade Federal Fluminense, Brasil

Suzete Venturelli

Universidade de Brasília, Brasil

Valério Cruz Brittos

Universidade do Vale do Rio dos Sinos, Brasil

Veneza Mayora Ronsini

Universidade Federal de Santa Maria, Brasil

Vera Regina Veiga França

Universidade Federal de Minas Gerais, Brasil
COMISSÃO EDITORIAL

Ana Gruszynski I Universidade Federal do Rio Grande do Sul, Brasil

Rose Melo Rocha I Escola Superior de Propaganda e Marketing, Brasil

CONSULTORES AD HOC

Alberto Schneider I Visitante Tokyo University

Alexandre Rocha da Silva I Universidade Federal do Rio Grande do Sul, Brasil

Fernanda Bruno I Universidade Federal do Rio de Janeiro, Brasil

Ida Stumpf I Universidade Federal do Rio Grande do Sul, Brasil

Kati Caetano I Universidade Tuiuti do Paraná, Brasil

Laura Cánepa I Universidade Anhembi Morumbi, Brasi

Malena Contrera I Universidade Paulista, Brasil

Sandra Gonçalves I Universidade Federal do Rio Grande do Sul, Brasil

Vicente Gosciola I Universidade Anhembi Morumbi, Brasil

REVISÃO DE TEXTO E TRADUÇÃo I Everton Cardoso

EDITORAÇ̃̃o ELETRÔNICA I Raquel Castedo
COMPós I www.compos.org.br

Associação Nacional dos Programas de Pós-Graduação em Comunicação

Presidente

Erick Felinto de Oliveira

Universidade do Estado do Rio de Janeiro, Brasil erickfelinto@uol.com.br

Vice-presidente

Ana Silvia Lopes Davi Médola

Universidade Estadual Paulista, Brasil

asilvia@faac.unesp.br

Secretária-Geral

Denize Correa Araújo

Universidade Tuiuti do Paraná, Brasil

denizearaujo@hotmail.com 